\title{
Epidemiology of bicycle injury, head injury, and helmet use among children in British Columbia: a five year descriptive study
}

\author{
S Linn, D Smith, S Sheps, of the Canadian Hospitals Injury Reporting and Prevention \\ Program (CHIRPP)
}

Department of
Epidemiology,
Rambam Medical
Center and Faculty of
Medicine, Technion,
Haifa, Israel,
Evaluation Sciences
Centre, British
Columbia Research
Institute for Child and
Family Health, British
Columbia Children's
Hospital, and the
Department of Health
Care and
Epidemiology,
University of British
Columbia, Vancouver,
British Columbia,
Canada
S Linn

British Columbia Children's Hospital D Smith

Department of Health Care and

Epidemiology, University of British Columbia

S Sheps

Correspondence to: Dr Shai Linn, Department of Epidemiology, Rambam Medical Center, Faculty of Medicine, Technion, and PO Box 9602 Haifa, Israel

(e-mail:linn@tx.technion.ac.il).

\begin{abstract}
Objectives and methods-Data on 1462 injured bicyclists aged 1-19, obtained over a period of five years from the British Columbia Children's Hospital as part of a national emergency room based program in Canada, were analyzed to describe the epidemiology of injuries, helmet use, and the occurrence of head injuries before the enactment of a new mandatory helmet law. The odds ratio (OR) and $95 \%$ confidence interval (CI) were calculated for non-users compared with helmet users. Results-Bicycle injuries comprised $4 \%$ of all injuries seen in the five year study period. The proportion of admissions was $12.7 \%$ among bicyclists, significantly higher than the $7.9 \%$ admissions of all 35323 non-bicyclist children who were seen during the study period $(O R=1.96$, $C I=1.44$ to 1.99 ). Boys were injured more often than girls. The proportion of admissions for boys was $13.8 \%$ compared with $10.2 \%$ among girls $(\mathrm{OR}=1.41, \mathrm{CI}=0.97$ to 2.05). More than $70 \%$ of injured bicyclists reported no helmet use. The proportion of admissions of injured bicyclists who did not use helmets was always higher than the proportion of admissions of those who used helmets $(\mathrm{OR}=2.23, \mathrm{CI}=1.39$ to 3.62). Head and face injuries occurred more often among those who did not use helmets $(\mathrm{OR}=1.55, \mathrm{CI}=1.18$ to 2.04$)$. However, there was no excess of minor head injuries among non-users (OR = $1.10, \mathrm{CI}=0.60$ to 2.06). Of the 62 concussions, 57 occurred to non-helmet users $(O R=4.04, C I=1.55$ to 11.47$)$. Most injuries occurred in the upper $(46.4 \%)$ or lower extremities (32.4\%). Dental injuries occurred slightly more often among helmet users compared with non-users but this excess was not statistically significant $(\mathrm{OR}=1.29, \mathrm{CI}=0.76$ to 2.20$)$.

Conclusion-The data indicate the need to control injuries by using helmets. A decrease in the number of head injuries and their severity is expected when bicycle helmet use becomes law in British Columbia. (Injury Prevention 1998;4:122-125)
\end{abstract}

Keywords: bicycle; Canada; epidemiology

Bicycle related injuries are a major concern in Canada, ${ }^{1-10}$ British Columbia, ${ }^{2}$ and elsewhere. ${ }^{11-20}$ One of the untoward results of bicycle use is head injuries. Recent legislation made the use of helmets mandatory for all bicyclists in British Columbia starting in September 1996. Data on 1462 injured bicyclists aged 1-19, obtained over a period of five years (1991-95) from the British Columbia Children's Hospital (BCCH), were analyzed to describe the epidemiology of bicycle related injuries, helmet use, and the occurrence of head injuries before the enactment of the mandatory helmet law.

\section{Methods}

The Canadian Hospitals Injury Reporting and Prevention Program (CHIRPP) is an emergency room based surveillance system. ${ }^{4}$ CHIRPP is organized and administered by the Laboratory Centre for Disease Control, Health Protection Branch, Health and Welfare Canada.

The parent or person who accompanies the injured child to the emergency room receives a CHIRPP questionnaire about the injury event, including demographic information, the time, location, activities being undertaken preceding the incident, and events that could be contributing factors to the injury. The attending physician completes a medical questionnaire indicating the nature of the injuries and the affected body part(s). Up to three injuries can be recorded per visit. Finally, the management of the child in the emergency room is recorded. The information is coded by a trained data entry clerk, based on a detailed CHIRPP manual. ${ }^{4}$ Specifically, loss of control was coded when "child lost control of bicycle which then resulted in his falling", collision refers to "collision between moving objects" (one of them a bicycle).

"Traffic accident" was defined as motor vehicle accidents and road traffic accidents. Medical conditions, such as "concussion", "brain injury", etc, were based on written indications by the physicians.

The data were analyzed using the CHIRPP software. A standard set of reports can be generated, including information on demographic characteristics, breakdown event, nature of injury, and body parts affected.

The emergency department at the $\mathrm{BCCH}$ adds a unique component to the data collection by obtaining data from the hospital's intensive care unit, by including children who are admitted directly to the intensive care unit, thus bypassing the emergency room. This report includes all bicyclists who reached the emergency room or intensive care unit at $\mathrm{BCCH}$ 
Table 1 Bicycle injuries in British Columbia: age and gender 1991-95

\begin{tabular}{ccccl}
\hline Age (years) & Male (\%) & Female (\%) & Total (\%) & Malelfemale \\
\hline $1-4$ & $124(12.0)$ & $60(13.9)$ & $184(12.6)$ & 2.1 \\
$5-9$ & $431(41.8)$ & $197(45.7)$ & $628(43.0)$ & 2.2 \\
$10-14$ & $403(39.1)$ & $151(35.0)$ & $555(38.0)$ & 2.7 \\
$15-19$ & $72(7.0)$ & $23(5.3)$ & $95(6.5)$ & 3.1 \\
Total & $1031(100.0)$ & $431(100.0)$ & $1462(100.0)$ & 2.4 \\
\hline
\end{tabular}

Table 2 Bicycle injuries in British Columbia: selected characteristics (CHIRPP data 1991-95); results are number (\%)

\begin{tabular}{|c|c|c|c|c|c|}
\hline & \multicolumn{4}{|l|}{ Age (years) } & \multirow[b]{2}{*}{ Total } \\
\hline & $0-4$ & $5-9$ & $9-14$ & $15-19$ & \\
\hline \multicolumn{6}{|l|}{ Breakdown factor } \\
\hline Lost control & $121(65.8)$ & $414(65.9)$ & $345(62.2)$ & $61(64.2)$ & $941(64.4)$ \\
\hline Collision & $32(17.4)$ & $130(20.7)$ & $150(27.0)$ & $27(28.4)$ & $339(23.2)$ \\
\hline Falls & $25(13.6)$ & $73(11.6)$ & $40(7.2)$ & $6(6.3)$ & $144(9.8)$ \\
\hline Traffic accident & $3(1.6)$ & $38(6.1)$ & $49(8.8)$ & $12(12.6)$ & $102(7.0)$ \\
\hline Occurrence on weekend & $63(34.2)$ & $205(32.6)$ & $175(31.5)$ & $29(30.5)$ & $472(32.3)$ \\
\hline \multicolumn{6}{|l|}{ Locations } \\
\hline Public road & $96(52.2)$ & $447(71.2)$ & $426(76.8)$ & $68(71.6)$ & $1037(70.9)$ \\
\hline Home injury & $45(24.5)$ & $65(10.4)$ & $21(3.8)$ & $2(2.1)$ & $133(9.1)$ \\
\hline Public playground & $12(6.5)$ & $40(6.4)$ & $27(4.9)$ & $1(1.1)$ & $80(5.5)$ \\
\hline School playground & 0 & $20(3.2)$ & $18(3.2)$ & $6(6.3)$ & $44(3.0)$ \\
\hline Helmet used & $29(15.8)$ & $153(24.4)$ & $118(21.3)$ & $27(28.4)$ & $327(22.4)$ \\
\hline Admitted & $10(5.4)$ & $81(12.9)$ & $81(14.6)$ & $14(14.7)$ & $186(12.7)$ \\
\hline Total patients & $184(100.0)$ & $628(100.0)$ & $555(100.0)$ & $95(100.0)$ & $1462(100.0)$ \\
\hline
\end{tabular}

between 1991-95. However, deaths that occurred outside hospital are not recorded.

Children were classified into four age groups for the analyses: 0-4 years (infants and preschoolers), 5-9 years (young school age children), 10-14 years (older school age children), and 15-19 years (adolescents). Data were obtained from all 1462 bicyclists injured during the study period (1031 boys and 431 girls). One male child was dead on arrival because of a serious head injury. During the study period, 186 injured bicyclists, 44 girls and 142 boys (about $12.7 \%$ ), were admitted. Separate analyses were performed for this subset of injured bicyclists. Those who did not use helmets were compared with helmet users. The odds ratio (OR) and the $95 \%$ confidence inter- val (CI) were calculated to estimate the risk of injuries and admissions.

\section{Results}

Most injuries involved children aged 5-14, with a decreasing frequency of injuries in older children. There were more boys than girls in all ages and the male/female ratio increased with age, ranging from 2.1 among children 1-4 years of age to $2.2,2.7,3.1$ in the other age groups, respectively, a statistically significant trend $(\mathrm{p}<0.0274)$ (table 1$)$. Bicycle related injuries were $4.0 \%$ of all 36785 injuries seen at $\mathrm{BCCH}$ during the study period.

The percentage of injuries on the weekend was higher $(34.2 \%)$ among the younger children, aged 1-4, compared with children aged $15-19(30.5 \%, \mathrm{p}<0.05)$ (table 2$)$. The average occurrence during the weekend was $32.3 \%$, higher than the anticipated $28 \%$, had the distribution of injuries been consistent for all days of the week.

MECHANISM OF INJURY, BREAKDOWN FACTOR, CONTEXT OF THE INJURY, AND HELMET USE (TABLE 2 AND TABLE 3)

Loss of control or falls were the most important cause of bicycle injury in all ages. Collisions occurred more often among boys and falls among girls. Most injuries occurred in public areas, while a minority occurred in residential areas. The percentage of residential or playground bicycle injuries decreased dramatically with increasing age.

More than $70 \%$ of patients did not use helmets. Helmet use was the lowest among children below age 5 and highest among those aged 15-19. The rate of reported helmet use among injured bicyclists increased consistently from $4.9 \%$ in 1991 to $32.1 \%$ in 1995 . Traffic accidents involving automobiles occurred in 102 patients $(7 \%)$ and increased with age. Of these, only 18 reported using a helmet.

Table 3 Bicycle injuries in British Columbia: selected characteristics (CHIRPP data 1991-95); results are number (\%)

\begin{tabular}{|c|c|c|c|c|c|}
\hline & \multicolumn{4}{|l|}{ Age (years) } & \multirow[b]{2}{*}{ Total } \\
\hline & $0-4$ & $5-9$ & $10-14$ & $15-19$ & \\
\hline \multicolumn{6}{|l|}{ Organs injured } \\
\hline Head and face & $90(48.9)$ & $288(45.9)$ & $162(29.2)$ & $28(29.5)$ & $568(38.9)$ \\
\hline Upper extremity & $45(24.5)$ & $257(40.9)$ & $320(57.7)$ & $56(58.9)$ & $678(46.4)$ \\
\hline Lower extremity & $47(25.5)$ & $168(26.8)$ & $216(38.9)$ & $44(46.3)$ & $475(32.5)$ \\
\hline Trunk & $3(1.6)$ & $34(5.4)$ & $33(5.9)$ & $2(2.1)$ & $72(4.9)$ \\
\hline Major organ & $6(3.3)$ & $27(4.3)$ & $11(2.0)$ & & $44(3.0)$ \\
\hline Kidney & & $2(0.3)$ & $2(0.4)$ & & $4(0.3)$ \\
\hline Liver & & $2(0.3)$ & $1(0.2)$ & & $3(0.2)$ \\
\hline Spleen & & $4(0.6)$ & $2(0.4)$ & & $6(0.4)$ \\
\hline Genitalia & $6(3.3)$ & $19(3.0)$ & $6(1.1)$ & & $31(2.1)$ \\
\hline Digestive tract & $12(6.5)$ & $28(4.5)$ & $7(1.3)$ & & $47(3.2)$ \\
\hline Mouth, gums, palate & $12(6.5)$ & $29(4.6)$ & $6(1.1)$ & & $47(3.2)$ \\
\hline Oesophagus & & & $1(0.2)$ & & $1(0.1)$ \\
\hline Small bowel & & $1(0.2)$ & & & $1(0.1)$ \\
\hline Minor head injury & $6(3.3)$ & $33(5.3)$ & $29(5.2)$ & $4(4.2)$ & $72(4.9)$ \\
\hline Concussion & $5(2.7)$ & $24(3.8)$ & $29(5.2)$ & $4(4.2)$ & $62(4.2)$ \\
\hline Brain & & $4(0.6)$ & $6(1.1)$ & $3(3.2)$ & $13(0.9)$ \\
\hline \multicolumn{6}{|l|}{ Nature of the injury } \\
\hline Superficial & $41(22.3)$ & $231(36.8)$ & $195(35.1)$ & $43(45.3)$ & $510(34.9)$ \\
\hline Fracture & $31(16.8)$ & $142(22.6)$ & $184(33.2)$ & $28(29.5)$ & $385(26.3)$ \\
\hline Dislocations, sprain, strain & $7(3.8)$ & $26(4.1)$ & $30(5.4)$ & $14(14.7)$ & $77(5.3)$ \\
\hline Dental & $9(4.9)$ & $53(8.4)$ & $17(3.1)$ & $3(3.2)$ & $82(5.6)$ \\
\hline Total & $184(100.0)$ & $628(100.0)$ & $555(100.0)$ & $95(100.0)$ & $1462(100.0)$ \\
\hline
\end{tabular}

Note: several injuies may occur to one patient. Categories are not mutually exclusive. 
In the study period, 186 children bicyclists were admitted (12.4\%). Compared with $7.9 \%$ admissions of all 35323 non-bicyclist children who were seen for treatment of other kinds of injuries during the study period, the proportion of admissions among bicyclists was significantly higher $(\mathrm{OR}=1.6, \mathrm{CI}=1.4$ to 2.0$)$. The proportion of admissions increased with age but the trend was not statistically significant.

The proportion of admissions of injured bicyclists who did not use helmets was higher than the proportion of those who used helmets in each year between 1991-95, with an overall OR of 2.2 ( $\mathrm{CI}=1.4$ to 3.6). The proportion of admissions among bicyclists who were involved in road traffic accidents was $21.5 \%$, higher than for all other injuries $(\mathrm{OR}=5.4, \mathrm{CI}=3.4$ to 8.5$)$.

Many injuries were to the head and face (568, 38.9\%). These occurred more often among those who did not use a helmet $(\mathrm{OR}=$ $1.6, \mathrm{CI}=1.2$ to 2.0$)$. Of these, $13.0 \%$ were admitted (of 74 admitted children, 1-19 years old, and only eight reported helmet use).

Most injuries in all ages involved the upper $(46.4 \%)$ or lower extremities $(32.5 \%)$. Of these, $11.5 \%$ and $7.2 \%$, respectively, were admitted. About 5\% had injuries to the trunk: 72 injuries, mostly abrasions, bruises, inflammation, or bites. Of these, $26.4 \%$ were admitted including two pelvic fractures, and one spinal fracture. Forty four injuries occurred to major organs: there were four injuries of the kidney, three liver injuries, six spleen injuries, and 31 injuries of the external genitalia. Admission percentages were $75 \%, 67 \%, 100 \%$, and $1 \%$, respectively. Most of the 45 injuries of the digestive tract were injuries of the internal mouth, $10.6 \%$ of whom were admitted.

There were $72(4.9 \%)$ minor head injuries, 57 of which occurred in non-helmeted cyclists (OR $=1.1, \mathrm{CI}=0.6$ to 2.1 ). Of these, two helmet users and four non-users were admitted. Twelve skull injuries occurred among non-helmeted children. Of the 62 concussions, 57 occurred to non-helmet users $(\mathrm{OR}=4.0, \mathrm{CI}=1.6$ to 11.5$)$. All but one child with a brain injury did not use helmets and all were admitted.

The most frequent type of injury was superficial cuts, which accounted for more than $35 \%$ of all patients. There were 385 fractures $(26.3 \%)$, of which $25.5 \%$ were admitted. These included 12 skull fractures, 256 fractures to upper extremities, and 68 fractures to lower extremities. There were 82 dental injuries ( $5.6 \%$ of all patients). Interestingly, dental injuries occurred slightly more often among helmet users compared with non-users but this excess was not statistically significant.

\section{Discussion}

Bicycle injuries continue to be a serious public health problem, comprising $4 \%$ of all injuries to children in the BCCH CHIRPP database during the study period, similar to the rate reported in Ontario ${ }^{3}$ and Alberta. ${ }^{8}$

The age and sex distribution and the injured organs reported in this study are similar to previous reports ${ }^{1-15}$; most bicycle related injuries are caused by falls and most involve the extremities, occurring more often among boys aged 5-15. More bicycle injuries occurred during the weekend, possibly because of more bicycle use at that time.

The proportion of admissions of bicyclists was higher than the percentage of other children seen at the BCCH. This indicates the more serious injuries to bicyclists compared with other types of injuries. Among bicyclists, more children with traffic related injuries were admitted. Most admissions were for head and brain injuries or injuries to the extremities, similar to other reports. ${ }^{3-15}$

Reversed referral bias may have occurred, as some injuries not included in the study were treated at other hospitals in the Vancouver area. Thus, our findings probably underestimate the magnitude of bicycle related injuries, especially for children aged 15-19 years. The lower number of injuries in this age group may be because they were treated in general hospitals.

Emergency room data often lack information on more serious injuries that reach the intensive care unit directly. However, the British Columbia CHIRPP data are unique in that they include all intensive care unit data since July 1992. Thus, the study may include more serious injuries, but underestimate those that are less severe. ${ }^{11}$

As has been reported by others, ${ }^{38}$ most injuries occurred because of loss of control and did not involve other vehicles. Thus, specific protection of bicyclists rather than implementation of motor vehicle traffic changes could be the most effective preventive strategy. It has been shown previously that head injuries can be prevented by wearing helmets and helmet nonuse has been shown to be strongly associated with severe head injury. ${ }^{1-27}$ This study confirms the protective effects of helmet wearing. The risk for head and face injury, skull injury, brain injury and concussion, as well as admittance for those injuries (which indicates the severity of these injuries) were statistically significantly increased for those who did not wear a helmet. This higher risk of head injury for non-users of helmets is consistent with other reports from Canada, ${ }^{1-10}$ the US, ${ }^{16}$ England, ${ }^{17}$ Australia, ${ }^{18}$ New Zealand, ${ }^{19}$ and Israel. ${ }^{20}$

Helmet use increased consistently during the study period in British Columbia, similar to the general trend in Canada. ${ }^{21}$ However, more than $70 \%$ of all injured bicycle users did not report wearing a helmet. Helmet use was lower among younger children, which may indicate a need for special helmets and more educational efforts for young children and their parents. Like previous publications ${ }^{28-31}$ this study indicates more injuries for boys than girls.

Reporting of helmet use could be randomly misclassified. Moreover, seriously injured children bicyclists (or their parents) may be unable to provide information on helmet use. If so, the bias would tend toward a lower risk for non-users. Thus, misclassification or biased reporting by more seriously injured children is unlikely to explain the findings of this study.

Interestingly, more of the helmet users suffered dental injuries, although the association did not reach statistical significance. The 
potential risk of maxillofacial injuries to bicyclists has been described recently by researchers in Australia ${ }^{18}$ and in Seattle. ${ }^{32}$ Although the five year CHIRPP data in British Columbia do not allow an evaluation of this risk because of small numbers, this question deserves further investigation and may lead to the development of different types of bicycle helmets that protect the jaws.

Many bicycle related injuries to children can be prevented by changing attitudes and knowledge, and head injuries can be more easily prevented by wearing protective helmets. Legislation, ${ }^{33}{ }^{34}$ together with education, ${ }^{3536}$ could be the best approach to reduce the pain and suffering, as well as the costs ${ }^{21}{ }^{37}$ of medical treatments that result from these injuries.

1 MacWilliam L, Mao Y, Nicholls E, et al. Fatal accidental childhood injuries in Canada. Can $\mathcal{f}$ Public Health 1987;78:129-35.

2 Brown B, Farley C. The pertinence of promoting the use of bicycle helmets for 8 to 12 year-old children. Chronic Diseases in Canada 1989;10:92-5.

3 Cushman R, Down J, MacMillan N, et al. Bicycle-related injuries: a survey in pediatric emergency department. Can injuries: a survey in pediatric eme

4 Laboratory Centre for Disease Control. Children's Hospitals Injury Research and Prevention Program CHIRPP. Technical report \#2. Ottawa: Health and Welfare Canada, Laboratory Centre for Disease Control, Bureau of Chronic Disease Epidemiology, 1991.

5 Blair L. CMA launches bicycle-helmet campaign hopes to reduce roadside carnage. Can Med Assoc f 1991;114:14989.

6 Shanon A, Bashaw B, Lewis J, et al. Nonfatal childhood injuries: a survey at the Children's Hospital of Eastern Ontario. Can Med Assoc F 1992;146:361-5.

7 Office for Injury Prevention, British Columbia Ministry of Health. Injury facts and prevention strategies for children and youth in British Columbia. Victoria: Office for Injury Prevention, British Columbia Ministry of Health, September 1993.

8 Finvers KA, Strother RT, Mohtadi N. The effect of bicycling helmets in preventing significant bicycle-related bicycling helmets in preventing significant bicycle-rela

9 Schwartz HJ, Brison RJ. Bicycle-related injuries in children. A study in two Ontario emergency departments, 1994 . A study in two Ontario emergency depa

10 Pless IB, Verreault R, Tenina S. A case-control study of pedestrian and bicyclist injuries in childhood. Am F Public Health 1996;79:995-9.

11 Friede AM, Azzara CV, Gallagher SS, et al. The epidemiology of injuries to bicycle riders. Pediatr Clin North Am 1985:32:141-51.

12 Thompson RS, Rivara FP, Thompson DC. A case control study of effectiveness of bicycle safety helmets. $N$ Engl Med 1989;320:1361-7.

13 Thompson DC, Thompson RS, Rivara FP. Incidence of bicycle-related injury in defined population. Am f Public Health 1990;80:1388-9.

14 Statts JC, Williamson JE, Whitley T, et al. Bicycle accidents and injuries: a pilot study comparing hospital- and policereported data. Accid Anal Prev 1990;22:67-78.
15 Baker PB, Li G, Fowler C, et al. Injuries to bicyclists: a national perspective. The Johns Hopkins Injury Prevention Center. BMF 1994;308:173-6.

16 National Center for Injury Prevention and Control, Centers for Diseases Control and Prevention. Injury-control recommendations: bicycle helmets. MMWR Morb Mortal Wkly Rep 1995;44:1-7.

17 Mimaris C, Summers CL, Browning C, et al. Injury patterns in bicyclists attending an accident and emergency department: a comparison of helmet wearers and nondepartment: a comparison of helm
wearers. BMF 1994;308:1537-40.

18 Acton H, Nixon JW, Clark RC. Bicycle riding and oral/maxillofacial trauma in young children. Med $\mathcal{F}$ Aust 1996;165:249-51.

19 Scuffham PA, Langley JD. Trends in cycle injury in New Zealand under voluntary helmet use. Accid Anal Prev 1997; 29:1-9.

20 Ginsberg GM, Silverberg DS. A cost-benefit analysis of legislation for bicycle safety helmets in Israel. Am f Public Health 1994;84:653-6.

21 Health Canada. CHIRPP Newsletter 1995, issue 6, November. Available on the internet at: http://www.hwc.ca:80/ $\mathrm{hpb} /$ publicat/chirpp

22 Spaite DW, Murphy M, Criss EA, et al. A prospective analysis of injury severity among helmeted and nonhelmeted bicyclists involved in collisions with motor vehicles. $f$ Trauma 1991:31:1510-14.

23 Maring W, van-Schagen I. Age dependence of attitudes and knowledge in cyclists. Accid Anal Prev 1990;22:127-36.

24 Ottis J, Lesage D, Godin G, et al. Predicting and reinforcing children's intentions to wear protective helmets while bicycling. Public Health Rep 1992;107:283-9.

25 MacDermott FT, Lane JC, Brazenor GA, et al. The effectiveness of bicyclist helmets: a study of 1710 casualties. F Trauma 1993;34:834-45.

$26 \mathrm{Head}$ and face injuries in bicyclists - with special reference to possible effects of helmet use. F Trauma 1992;33:88793

27 Runyan CW, Runyan DK. How can physicians get kids to wear bicycle helmets? A prototypic challenge in injury prevention. Am f Public Health 1991;81:972-3.

28 Waldron I. Sex differential in illness incidence, prognosis and mortality: issues and evidence. Soc Sci Med 1983;17: $1107-23$

29 Guyer B, Gallagher SS. An approach to the epidemiology of childhood injuries. Pediatr Clin North Am 1985;32:5-15.

30 Hull C. Gender and childhood injury. Victoria: British Columbia Ministry of Health, 1991.

$31 \mathrm{Hu} \mathrm{X}$, Wesson DE Chipman ML, et al. Bicycling exposure and severe injuries in school-age children. A populationbased study. Arch Pediatr Adolesc Med 1995;149:437-41.

32 Thompson DC, Diane C, Nunn ME, et al. Effectiveness of bicycle safety helmets in preventing serious facial injury. fAMA 1996;276:1974-6.

33 Vulcan AP, Cameron MH, Watson WL. Mandatory bicycle helmet use: experience in Victoria, Australia. World f Surg 1992;16:389-97.

34 Thomas S, Acton C, Nixon J, et al. Effectiveness of bicycle helmets in preventing head injury in children: case-control study. BMf 1994;308:173-6.

35 Rivara FP, Thompson DC, Thompson RS, et al. The Seattle children's bicycle helmet campaign: changes in helmet use and head injury admissions. Pediatrics 1994;93:567-9.

36 Sosin DM, Sacks JJ, Webb KW. Pediatric head injuries and deaths from bicycling in the United States. Pediatrics 1996; 98:868-91.

37 Barlam C. Impact of chronic diseases on the health of Canadians: a case for prevention. Chronic Diseases in Canada 1989;10:42-4. 